\title{
ANALISIS GEOMETRI FRAKTAL PADA BENTUK BANGUNAN DI KOMPLEK KERATON KANOMAN CIREBON
}

\author{
Siska Firmasari ${ }^{1)}$, Herri Sulaiman ${ }^{2)}$, \\ 1) FKIP Universitas Swadaya Gunung jati (UGJ), JL. Perjuangan No.1, Kel. Karyamulya, \\ Kec. Kesambi, Kota Cirebon, Jawa Barat 45132. Email: siskafs@fkip-unswagati.ac.id \\ 2) FKIP Universitas Swadaya Gunung jati (UGJ), JL. Perjuangan No.1, Kel. Karyamulya, \\ Kec. Kesambi, Kota Cirebon, Jawa Barat 45132. Email: herrimsc@gmail.com
}

\begin{abstract}
Keraton comes from the ancient Javanese language, namely the word keratuan showing place information, namely to reside in the king or the residence of the king. The king as head of government resides in the palace which is made the centre of the kingdom and all political, economic, social and cultural activities. High-ranking royal officials and nobles also lived in the vicinity. Because almost all community activities are centred around the palace, it develops into a city. The Keraton Kanoman was built in $1588 \mathrm{M}$ by prince Muhamad Badarudin Kertawijaya who held the title Sultan Anom I. He set up his Keraton at the house of Prince Cakrabuana when he had just arrived at the tegal Alang-Alang called Witana. Titimangsa year the founding of the Keraton Kanoman is written in an image at the entrance of the Keraton Kanoman Jinem, which describes the sun means one, wayang Darma Kusuma which means five, the earth means one, and an animal which means zero. The Candrasangkala shows the numbers in 1510 Saka or $1588 \mathrm{M}$. So the Keraton Kanoman was founded in 1510 Saka or 1588 M. This study aims to reveal fractal geometry in the Keraton Kanoman complex which is seen in aspects of fractal dimensions of the building form. Fractal dimension analysis uses the boxcounting method to determine the level of roughness of buildings in the Keraton Kanoman complex by sketching several scales. This research method is ethnography and the type of research is qualitative descriptive. The data collection technique is done by interview, observation and documentation. The results showed that the shape of the building from the Lawang seblawong, Balai manguntur, and gapura Barat had fractal dimension depth with a fairly high level of roughness. Consequently, the details of the structure are classified as high.
\end{abstract}

Keywords. Keraton, Kanoman, Geometry Fractal

\section{Pendahuluan}

Keraton berasal dari bahasa Jawa kuno keratuan dengan kata dasar ratu, mendapat awalan ke dan akhiran an. Kata ratu berarti raja. Kata keratuan menunjukkan keterangan tempat yaitu tempat bersemayamnya raja atau tempat kediaman raja. Terkait dengan arti keraton, Soeratman mengatakan

Euclid, p-ISSN 2355-1712, e-ISSN 2541-4453, Vol. 7, No. 1, pp. 1- 76

CLembaga Penelitian Universitas Swadaya Gunung Jati (UGJ), Cirebon. 
bahwa keraton merupakan istilah yang mempunyai beberapa arti, pertama berarti negara atau kerajaan dan kedua, sebagai pekarangan raja, meliputi wilayah di dalam Cepuri Baluwerti (Cepuri berarti tembok yang mengelilingi halaman). Baluwerti/Baluarti (bahasa Portugis berarti benteng) atau ditambah dengan alun-alun (Huda NT, 2018). Keraton merupakan kumpulan bangunan tempat bersemayam raja dan keluarganya. Raja sebagai kepala pemerintahan selalu tinggal di dalam keraton yang biasanya dijadikan sebagai pusat kerajaan dan segala kegiatan politik, ekonomi, sosial, dan budaya. Para pejabat tinggi kerajaan dan bangsawan biasanya juga tinggal di sekitar istana. Karena hampir semua kegiatan terpusat di sekitar keraton, maka tempat kediaman raja tersebut kemudian berkembang menjadi kota (Sucipto T, 2010). Secara rinci arti keraton adalah: Keraton sebagai kerajaan atau negara berarti peran keraton untuk menggarap sisi manusianya. Keraton (keratuan) merupakan tempat sang pemimpin, si pemimpin, sarana penyelenggaraan kepemimpinan. Peran keraton adalah mengembangkan sumber daya manusia.

Di Cirebon terdapat tiga keraton yang kondisinya masih utuh, yaitu Kasepuhan, Kanoman, dan Kacirebonan. Dari rentetan silsilahnya, ketiga keraton tersebut masih satu keturunan dari Sunan Gunung Jati. Dari ketiga keraton yang ada, penelitian ini akan difokuskan pada keraton Kanoman. Alasannya, karena keraton Kanoman masih jarang ditulis, baik di surat kabar maupun buku-buku penelitian, kalau pun ada tulisan mengenai keraton Kanoman hanya mengungkap masalah upacara panjang jimat. Komplek bangunan di sekitar keraton Kanoman tidak lepas dari bentuk ukiran dan hiasan keramik dari Cina (Rosmalia D \& L Edhi P, 2017). Berikut ini diberikan tabel mengenai nama bangunan dan fungsi yang ada di sekitar komplek keraton Kanoman.

Tabel 1. Bangunan di Sekitar Komplek Keraton Kanoman

\begin{tabular}{lcl}
\hline No. & Nama Bangunan & \multicolumn{1}{c}{ Fungsi } \\
\hline 1. & lawang seblawong & Pintu gerbang yang dibuka pada waktu \\
& perayaan Maulid Nabi Muhammad SAW. \\
2. $\quad$ mande manguntur & Tempat palinggihan raja sewaktu menghadiri \\
& dan menyaksikan upacara sakral seperti apel \\
& prajurit, pemukulan perdana gamelan sekaten \\
& setiap tanggal 8 Maulud. Balai ini juga \\
& digunakan raja untuk menyampaikan berita \\
& atau pun wejangan, hukum, aturan agama \\
& kepada masyarakat. \\
& Pintu masuk menuju mande manguntur berada \\
& di sisi sebelah barat. \\
\hline &
\end{tabular}


Masalah yang diangkat dalam penelitian ini adalah bagaimana geometri fraktal dalam bentuk susunan bangunan yang ada di sekitar komplek keraton Kanoman. Tujuan penelitian ini untuk menganalisis dimensi fraktal dari susunan bangunan yang ada di sekitar komplek keraton Kanoman yaitu untuk bangunan lawang seblawong, balai manguntur, dan gapura barat dengan menggunakan metode box-counting. Tujuan menganalisis dimensi fraktal ialah untuk mengetahui tingkat kedalaman, kedetailan dan kekasaran dari susunan bangunan keraton apakah berkriteria sedang, tinggi atau rendah.

\section{Metode Penelitian}

Penelitian ini menggunakan metode etnografi dengan teknik pengumpulan data dilakukan dengan wawancara, observasi dan dokumentasi. Observasi dan wawancara dilakukan kepada narasumber keluarga keraton dengan mengamati dan memberikan penejelasan makna dan filosofis berbagai macam objek bangunan di sekitar keraton Kanoman. Metode yang digunakan dalam menghitung dan menganalisis geometri fraktal ialah metode boxcounting. Metode ini berupa prosedur penaksiran untuk menghitung dimensi fraktal dari objek yang rumit. Metode ini digunakan jika tidak dapat menentukan panjang segmen atau kemiringan dari benda-benda yang berbentuk unik. Contohnya ialah menghitung dimensi debu, ombak laut dan awan. (Budiarto MT, 2014). Berikut ini diberikan persamaan umum dari BoxCounting method.

$$
D=\frac{\ln n(a)-\ln n(b)}{\ln ^{1} / s_{a}-\ln ^{1} / s_{b}}
$$

Dengan :

$$
\begin{array}{ll}
n & : \text { jumlah persegi/grid yang tertutupi kurva } \\
1 / S & : \text { skala grid }
\end{array}
$$

\section{Hasil dan Pembahasan}

\subsection{Geometri Fraktal pada Bentuk Bangunan di Komplek Keraton Kanoman}

Geometri menjadi suatu hal yang sangat penting dalam perancangan arsitektur sebagai alat untuk mendefinisikan ruang. Seperti yang diketahui geometri merupakan sebuah order yang memimpin perancang dalam prosesnya secara efisien mencapai sesuatu yang diinginkan menjadi 'indah'. Aturan-aturan yang ada tersebut kelihatannya mengikat dan mengarahkan suatu perancangan ke satu tujuan tertentu. Tetapi, sesuai pernyataan di atas, tanpa adanya aturan tertentu arsitek hanya akan menjadi sebatas tukang batu yang menyusun batu-batu sehingga menjadi hasil yang tanpa makna. Sebaliknya, ketika perancang memutuskan untuk memegang satu 'aturan'

Euclid, p-ISSN 2355-1712, e-ISSN 2541-4453, Vol. 7, No. 1, pp. 1- 76

(CLembaga Penelitian Universitas Swadaya Gunung Jati (UGJ), Cirebon. 
tertentu yang cocok dengan jiwanya dan tentu saja jiwa lingkungannya (Maron S, 2017). Geometri fraktal adalah geometri alam yang memliki bentukan irregular. Geometri alam tidak sepenuhnya tidak terukur. Fraktal adalah cara mengindentifikasi bentuk irregular tersebut sehingga terukur. Dalam prinsip fraktal menggunakan cara menskala bentukan pada tiap fragmen bentukan. Konsep dari dimensi fraktal adalah memainkan aturan tertentu dalam penggunaannya (Sayekti SI \& Chairil Budiarto, 2017).

Dalam kajian kali ini identifikasi bentuk bangunan komplek keraton Kanoman akan menggunakan proporsi dan perbandingan bagian fasad dan plan, sehingga ditemukan prinsip geometri perbandingan yang tepat. Geometri fraktal dalam arsitektur dapat menghasilkan ide yang indah dan kompleks mempunyai energi universal yang kuat terpantul pada bangunan. Candi Hindu merupakan contoh terbaik dari penerapan geometri fraktal dari masa lampau dengan pandangan religi kosmis, yang sebenarnya telah ada sebelum ditemukannya teori geometri fraktal. Geometri fraktal digunakan untuk memanifestasi atau mentransformasikan Hindu kosmologi dan fisiologi kedalam diagram vastu purusha mandala. Vastu mengacu pada lingkungan fisik. Purusha mengacu pada energi atau mahluk kosmis, sedangkan mandala adalah diagram atau grafik. Bagian tengah mandala adalah tempat Brahmana sebagi energi cosmis terbesar terpusat ditengah berpentuk persegi yang teraplikasi pada struktur candi (Sayekti SI \& Chairil B, 2017).

Fraktal memiliki karakteristik self-similary yang berarti fraktal memiliki sifatsifat yang sama untuk berbagai skala yang digunakan. Dimensi fraktal berupa bilangan pecahan yang dapat digunakan sebagai pengidentifikasi ciri suatu citra. Dimensi fraktal dalam geometri fraktal adalah perhitungan yang mengukur nilai kefraktalan suatu objek. Untuk setiap fraktal objek dimensi fraktal selalu non-integer, yaitu tidak seperti benda berdimensi bulat (titik (nol dimensi), garis (satu dimensi), persegi (dua dimensi) dan kubus (tiga dimensi)) objek fraktal adalah pecahan-pecahan dimensi yang artinya objek fraktal dapat diantara satu dan dua dimensi atau diantara dua dimensi dan tiga dimensi. Sebab antara satu dimensi dan dua dimensi fraktal 'D' adalah selalu lebih dari satu dan kurang dari dua (i.e.,1 $<\mathrm{D}<2$ ), sedangkan objek diantara dua dan tiga dimensi fraktal ' $\mathrm{D}$ ' selalu lebih dari dua dan kurang dari tiga (i.e., $2<\mathrm{D}<3$ ). Jadi dimensi fraktal berupa pecahan bukan bilangan bulat (Maryati RC \& Indra P, 2018).

Dimensi fraktal dapat dihitung dengan metode perhitungan kotak (boxcounting). Metode ini membagi citra menjadi kotak-kotak dengan bervariasi ukuran. Box Counting Method adalah metode yang digunakan untuk mengevaluasi dimensi fraktal dari tampak bangunan, gunung, pohon atau 
benda yang tidak fraktal. Dimensi fraktal yang dihitung dengan box counting method mengukur kefraktalan dari suatu gambar atas dasar kekasaran, tekstur atau jumlah rincian gambar. Gambar yang memiliki dimensi fraktal 1,1- 1,5 menunjukan kurangnya rincian detailnya, sedangkan gambar yang memiliki dimensi fraktal 1,6-1,9 tetapi kurang dari nilai dua integer, menunjukan tingginya rincian detail gambar. Kekasaran gambar yang memiliki dimensi fraktal 1,21-1,25 atau dimensi 1,81-1,86 secara visual tidak begitu banyak dibedakan jika dilihat dengan mata telanjang. Pada dimensi fraktal 1.1,1.2, 1.3,..., 1,8 dan 1,9 dapat terlihat dengan jelas perbedaannya.

Lebih lanjut untuk mengevaluasi fraktal dari sebuah gambar dengan metode counting box ini dilakukan dengan beberapa langkah yaitu:

a. Grid persegi diletakan diatas gambar.

b. Skalakan grid 'S' pada gambar tersebut.

c. Hitung grid persegi tersebut yang tertandai oleh gambar. Jumlah grid adalah ' $\mathrm{N}$ '.

d. Ulangi proses dengan gambar yang sama, hanya saja ubah skala grid perseginya.

e. Dimensi fraktal ' $\mathrm{D}$ ' dapat dihitung dengan mengubah hasil ' $\mathrm{S}$ ' dan ' $N$ ' ke dalam grafik log-log, kemiringan garis yang dihasilkan dari grafik $\log -\log$.

f. Menentukan dimensi fraktal dari gambar.

\subsection{Hasil Perhitungan Dimensi Fraktal pada Bentuk Bangunan di Sekitar Komplek Keraton Kanoman}

Berikut ini diberikan hasil pehitungan dimensi fraktal dengan menggunakan metode Box Counting (grid method). Selanjutnya dapat dianalisis kedalaman, kekasaran dan kedetailan dari strukutur bangunan keraton tersebut. Adapun bangunan yang dianalisis adalah lawang seblawong, balai manguntur, dan gapura barat.

\subsubsection{Hasil Perhitungan Dimensi Fraktal Lawang Seblawong}

Berikut ini diberikan hasil sketsa dari bangunan lawang seblawong yang disusun berdasarkan skala grid. 


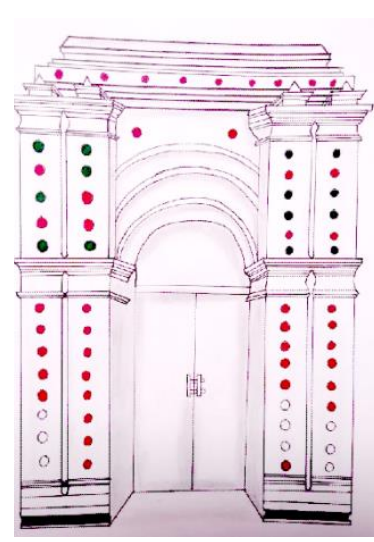

(1)

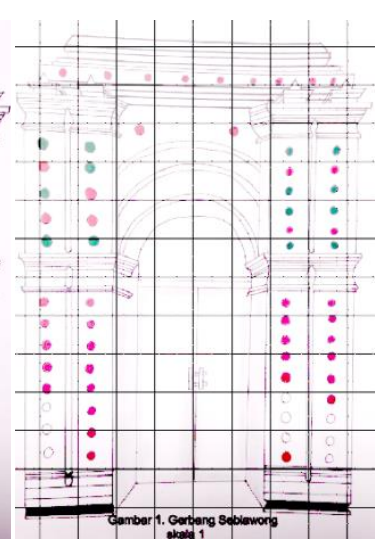

(2)

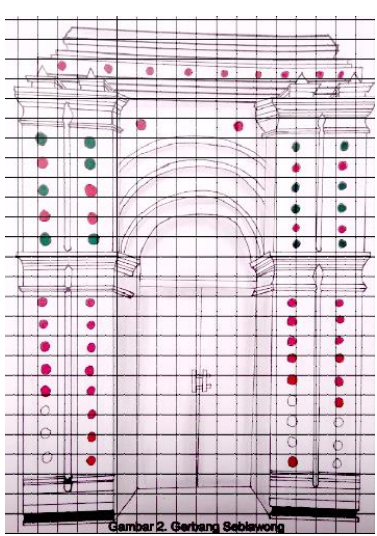

(3)

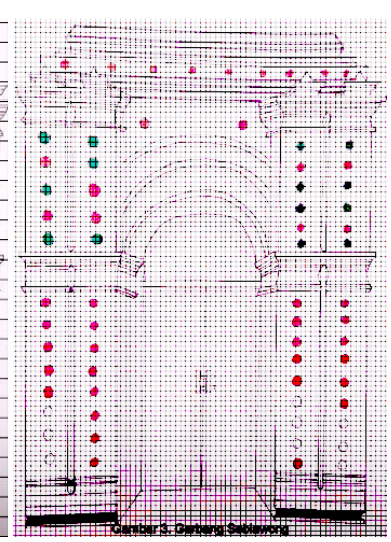

(4)

Gambar 2.

Pengaplikasian Box Counting pada gambar fraktal dengan objek Lawang Seblawong yang terdapat di dalam komplek Keraton Kanoman Cirebon; (1) grid ukuran 0, (2) grid ukuran 1, (3) grid ukuran 1/2, (4) grid ukuran 1/4

Selanjutnya adalah hasil perhitungan dimensi fraktal objek lawang seblawong menggunakan metode box-counting berdasarkan persamaan (1) berikut ini.

$$
\begin{array}{cl}
D & =\frac{\ln n(a)-\ln n(b)}{\ln ^{1} / s_{a}-\ln 1 / s_{b}} \\
D_{\text {grid }^{1} / 2^{, 1}} & =\frac{\ln 413-\ln 130}{\ln 2-0} \approx 1,66 \\
D_{\text {grid }^{1} / 4,1} & =\frac{\ln 1383-\ln 130}{\ln 4-0} \approx 1,38 \\
D_{\text {grid }^{1} / 4,1 / 2} & =\frac{\ln 1383-\ln 413}{\ln 4-\ln 2} \approx 1,74
\end{array}
$$

Dari perhitungan di atas dapat diketahui bahwa objek lawang seblawong memiliki kedalaman (dimensi fraktal) D mendekati 1,74. Artinya menunjukkan tingkat kekasaran dan detail pada bentuk geometri objek tersebut tergolong tinggi.

\subsubsection{Hasil Perhitungan Dimensi Fraktal objek Mande Manguntur}

Berikut ini diberikan hasil sketsa dari bangunan mande manguntur yang disusun berdasarkan skala grid. 


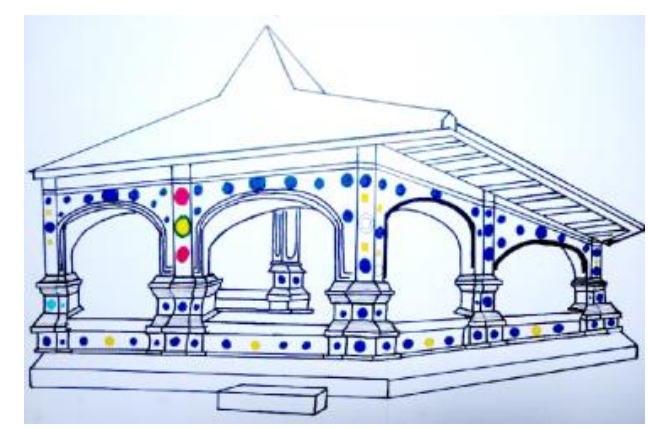

(1)

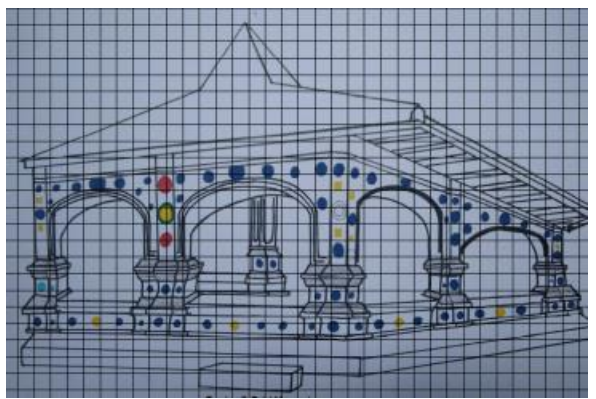

(3)

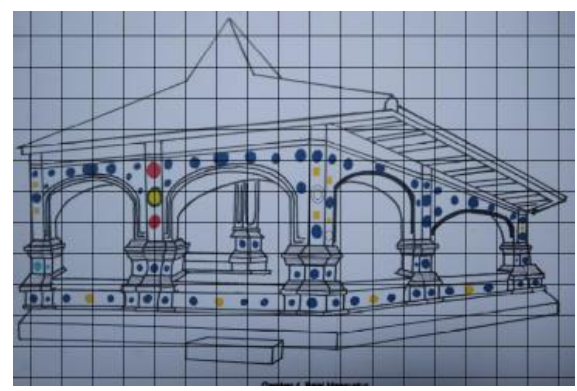

(2)

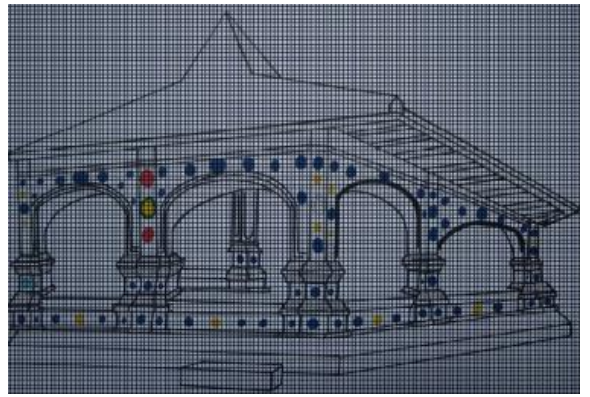

(4)

Gambar 3.

Pengaplikasian Box Counting pada gambar fraktal dengan objek Mande Manguntur yang terdapat di dalam komplek Keraton Kanoman Cirebon; (1) grid ukuran 0, (2) grid ukuran 1, (3) grid ukuran 1/2, (4) grid ukuran 1/4

Selanjutnya adalah hasil perhitungan dimensi fraktal objek mande manguntur menggunakan metode box-counting berdasarkan persamaan (1) berikut ini.

$$
\begin{array}{cl}
D & =\frac{\ln n(a)-\ln n(b)}{\ln ^{1} / s_{a}-\ln ^{1} / s_{b}} \\
D_{\text {grid }^{1} / 2^{, 1}} & =\frac{\ln 259-\ln 83}{\ln 2-0} \approx 1,64 \\
D_{\text {grid }^{1} / 4^{, 1}} & =\frac{\ln 917-\ln 83}{\ln 4-0} \approx 1,73 \\
D_{\text {grid } 1 / 4^{1}, 1} & =\frac{\ln 917-\ln 259}{\ln 4-\ln 2} \approx 1,82
\end{array}
$$

Dari perhitungan di atas dapat diketahui bahwa objek mande manguntur memiliki kedalaman (dimensi fraktal) D mendekati 1,82. Artinya menunjukkan tingkat kekasaran dan detail pada bentuk geometri objek tersebut tergolong tinggi.

\subsubsection{Hasil Perhitungan Dimensi Fraktal objek Gapura Barat}

Berikut ini diberikan hasil sketsa dari bangunan gapura barat yang disusun berdasarkan skala grid. 


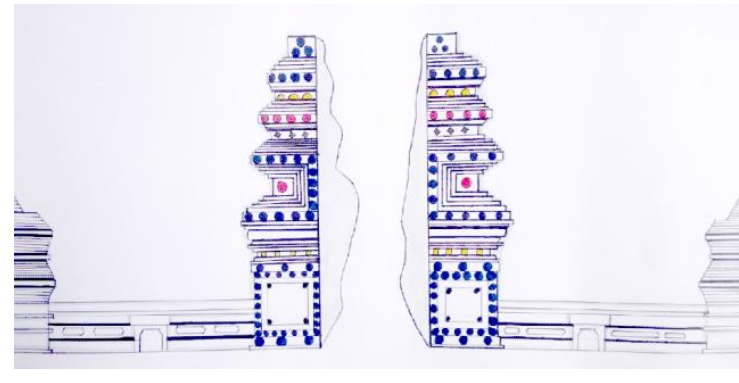

(1)

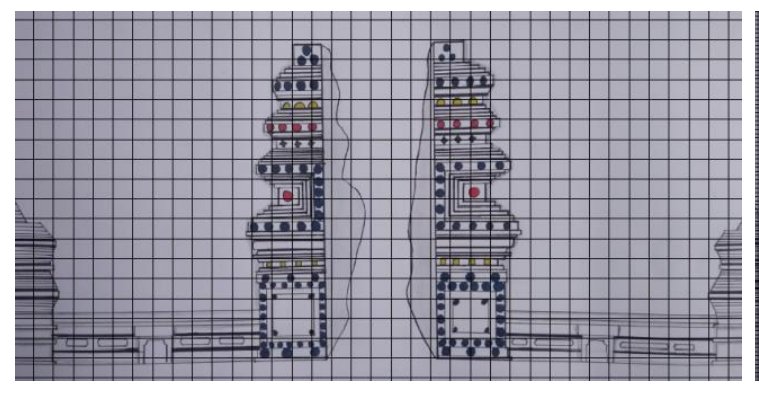

(3)

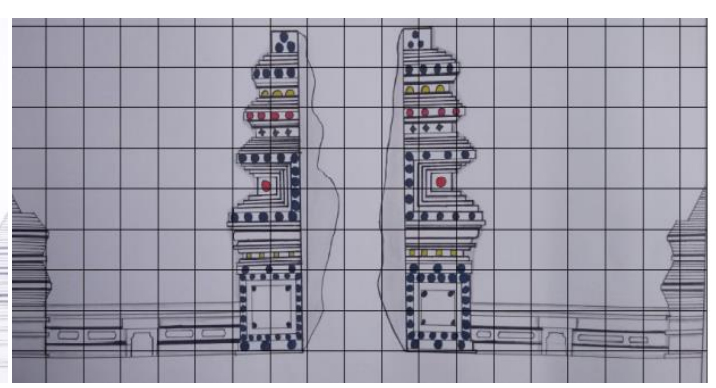

(2)

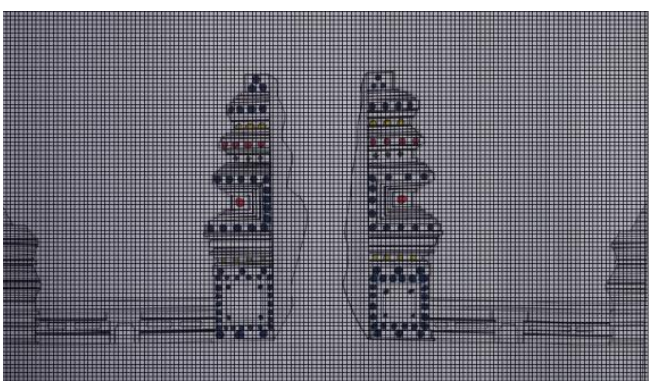

(4)

Gambar 4.

Pengaplikasian Box Counting pada gambar fraktal dengan objek Gapura Barat yang terdapat di dalam komplek Keraton Kanoman Cirebon; (1) grid ukuran 0, (2) grid ukuran 1, (3) grid ukuran 1/2, (4) grid ukuran 1/4

Selanjutnya adalah hasil perhitungan dimensi fraktal objek gapura barat menggunakan metode box-counting berdasarkan persamaan (1) berikut ini.

$$
\begin{array}{cl}
D & =\frac{\ln n(a)-\ln n(b)}{\ln ^{1} / s_{a}-\ln ^{1} / s_{b}} \\
D_{\text {grid }^{1} / 2^{, 1}} & =\frac{\ln 154-\ln 72}{\ln 2-0} \approx 1,09 \\
D_{\text {grid } 1 / 4,1} & =\frac{\ln 451-\ln 72}{\ln 4-0} \approx 1,32 \\
D_{\text {grid } 1 / 4,1 / 2} & =\frac{\ln 451-\ln 154}{\ln 4-\ln 2} \approx 1,55
\end{array}
$$

Dari perhitungan di atas dapat diketahui bahwa objek gapura barat memiliki kedalaman (dimensi fraktal) D mendekati 1,55. Artinya menunjukkan tingkat kekasaran dan detail pada bentuk geometri objek tersebut tergolong tinggi.

\section{Simpulan dan Saran}

Analisis dimensi fraktal bertujuan untuk mengetahui dimensi fraktal yang terdapat pada lawang seblawong, mande manguntur, dan gapura barat 
memperlihatkan bentukan dasar dan pola perulangan yang terbentuk pada sketsa. Analisis dimensi fraktal ini menggunakan metode counting box yang dapat dilihat tingkat kefraktalan suatu bangunan. Analisis visual ini sebatas objek tampak dan denah yang dilihat secara dua dimensi sehingga hasil dimensi yang diperoleh pada analisis ini tidak mungkin lebih dari dua dimensi. Hal ini tampak bahwa masing-masing objek bangunan keraton Kanoman memiliki kedalaman dimensi fraktal sebesar 1,74 untuk lawang seblawong, 1,82 mande manguntur, dan 1,55 untuk gapura barat dengan interpretasi kekasaran dan kedetailan objek bangunan tersebut tergolong tinggi.

Saran dari penelitian ini adalah perlu dilakukan kajian lebih dalam terkait selft similary yaitu salah satu ciri dari prinsip geometri fraktal. Adapun maksud dari similary selft adalah pengulangan kembali bentukan dasar yang sama pada skala bentuk dasar diperbesar ataupun diperkecil tetap terbentuk dari bentuk dasar yang sama. Lawang seblawong merupakan bentukan yang berulang bentuk geometrinya dari bentukan elemen menjadi satu bangunan yang komplek. Tampak menurut hasil analisis dimensi fraktal memiliki dimensi yang lebih tinggi dibanding denah, hal ini menunjukan bahwa perulangan geometri dasar pada lawang seblawong memiliki bentukan yang detail. Bentukan kubus yang mengalami perulangan diri sendiri (similary self) membentuk bentukan seperti pada bagian badan, kaki, dan puncak lawang seblawong merupakan bentukan dasar lawang seblawong dengan bentukan puncak pendukung.

\section{Daftar Pustaka}

Budiarto, MT. 2014. Sistem Geometri. Surabaya: Unesa Unipress.

Huda, NT. 2018. Kajian Aspek Geometri Fraktal Candi Prambanan dan Pengenalan Dimensi Fraktal pada Siswa SMA. Tesis Program Studi Pedidikan Matematika Universitas Sanata Darma Yogyakarta, 1-198.

Maron, Saiful. 2017. Application of Fractal Concept in Material Batik Development Based on Wolframs Mathematica. Zero, Jurnal SAINS Matematika dan Terapan, 1(2), 49-61.

Maryati, Rully C \& Indra P. 2018. Ethnomatematics: Exploring the Activities of Designing Kebaya Kartini. Mapan, Jurnal Matematika dan Pembelajaran, 6(1), 11-19. 
Rosmalia, Dini \& L. Edhi P. 2017. Kosmologi Elemen Lanskap Budaya Cirebon. Prosiding Seminar Heritage, 73-82.

Sayekti, SI \& Chairil Budiarto A. 2017. Geometri Fraktal Pada Candi Singosari Sebagai Konsep Desain Museum Purbakala Singosari. Jurnal Jurusan Arsitektur Universitas Brawijaya, 3-15.

Sucipto, Toto. 2010. Eksistensi Keraton di Cirebon Kajian Persepsi Masyarakat Terhadap Keraton-Keraton di Cirebon. Balai Pelestarian Sejarah dan Nilai Tradisional Bandung, 2(3), 472-489. 